Systematic Review

\title{
Work Environment, Spiritual, and Motivational Factors Affecting Job Satisfaction among Hospital Nurses: A Systematic Review
}

\section{Ida Yanriatuti, Tan Nina Fibriola, Kornelis Nama Beni and Fitriyanti Patarru'}

Faculty of Nursing, Universitas Airlangga, Surabaya, East Java, Indonesia

\begin{abstract}
Introduction: Patient services at the hospital cannot be separated from the role of the nurse. Therefore, nurses must work professionally to provide better nursing care. There are several factors that can affect the performance of the nurses, one of which is job satisfaction. The purpose of a systematic review is to understand the factors that influence the job satisfaction of nurses in hospitals.
\end{abstract}

Methods: For a systematic review, the search was focused on the PubMed, Science Direct and Scopus database literature with the keywords 'job satisfaction' and 'nurses'. The search identified 15 relevant research articles from the 10,530 original articles that were full texts published between 2015 and 2018.

Results: The results showed that the job satisfaction of the nurses was influenced by their leadership, work environment, career path, the relationship with their co-workers, salary, the relationship between the organizations, appreciation, communication, opportunity, organizational commitment, work schedule, work stress, empowerment and work rotation. The results also indicated that high job satisfaction leads to lowering nurse retention and burnout, in addition to an improved quality of patient care.

Conclusion: The nurse's job satisfaction needs to get serious attention from hospital management because it plays an important role in improving the health care service quality in the hospital.

\section{ARTICLE HISTORY}

Received: December 26, 2019

Accepted: December 31, 2019

\section{KEYWORDS}

work environment; spiritual; motivational

\section{CONTACT}

Ida Yanriatuti

$\triangle$ ida.yanriatuti-

2018@fkp.unair.ac.id

$\equiv$ Faculty of Nursing, Universitas

Airlangga, Surabaya, Indonesia

Cite this as: Yanriatuti, I., Fibriola, T. N., Beni, K. N., \& Patarru', F. (2019). Review Work Environment, Spiritual, and Motivational Factors Affecting Job Satisfaction among Hospital Nurses: A Systematic Review. Jurnal Ners, 14(3si), 227-230. doi:http://dx.doi.org/10.20473/jn.v14i3(si).17107

\section{INTRODUCTION}

Job satisfaction is an important factor in the healthcare setting. It is a predictor of patient care quality and safety internationally. Improving the nurses' job satisfaction and reducing their intention to leave is crucial to the stability of the nursing workforce (Biegger, De Geest, Schubert, \& Ausserhofer, 2016). As advances have been made in medicine and technology recently, patient care has become more complex. Nurses needed specialized knowledge, skills and health care delivery mechanisms to evolve and support the patients' needs for continuous monitoring and treatment(Abduelaal Abduelazeez \& Mohammed Nouri, 2016). Dissatisfaction with the work can cause poor job performance, lower productivity, staff turnover and increased costs to the organizations
(Akman, Ozturk, Bektas, Ayar, \& Armstrong, 2016). The nurse managers and policy makers should ensure adequate staffing, supplies and equipment to provide a positive and healthy practice environment, which is crucial to job satisfaction. The outcomes should provide important insights for policy makers on how to improve job satisfaction and other stakeholders in order to provide a deeper understanding of the factors that can influence job satisfaction. This is so then strategies can be developed on how best to manage the nursing workforce in the face of increasing pressure (Atefi, Abdullah, Wong, \& Mazlom, 2014). Previous research on the factors affecting nurse job satisfaction has been conducted. For this systematic review, job satisfaction has been represented by three main factors: the work environment, spirituality and motivational factors. We chose to conduct a systematic review to identify 
and summarize the currently available factors affecting nurse job satisfaction The aim of this systematic review is to understand the factors that influence the job satisfaction of the nurses in the hospitals.

\section{MATERIALS AND METHODS}

\section{Design}

This systematic review was conducted using the following steps based on the PRISMA Statement, which were as follows: (Biegger et al., 2016) formulating a research question, (Abduelaal Abduelazeez \& Mohammed Nouri, 2016) selecting the relevant search terms and formulating search phrases by consulting an information specialist in the field of health sciences, (Akman et al., 2016) planning a search strategy, (Atefi et al., 2014) agreeing on the inclusion and exclusion criteria, (Moher et al., 2009) conducting a systematic search in electronic databases, (Boamah, Spence Laschinger, Wong, \& Clarke, 2018) selecting eligible research articles and (Alostaz, 2016) performing a quality appraisal of the studies selected for the review (Moher et al., 2009). For a systematic review, the search of te PubMed, Science Direct and Scopus database literature was done with the keywords 'job satisfaction' and 'nurses'. The search identified 15 relevant research articles from the 10,530 original articles and full texts published from 2015 - 2018. The research articles were in PDF format, were a full text, were free to download and used English. Figure 1 shows the PRISMA flow chart.

\section{Searching Strategy and Inclusion Criteria}

A systematic search was conducted in the PubMed, Science Direct and Scopus databases in February 2019 resulting in 10,530 articles. The search was performed by employing combinations of the terms job satisfaction AND nurses. In order to be eligible for

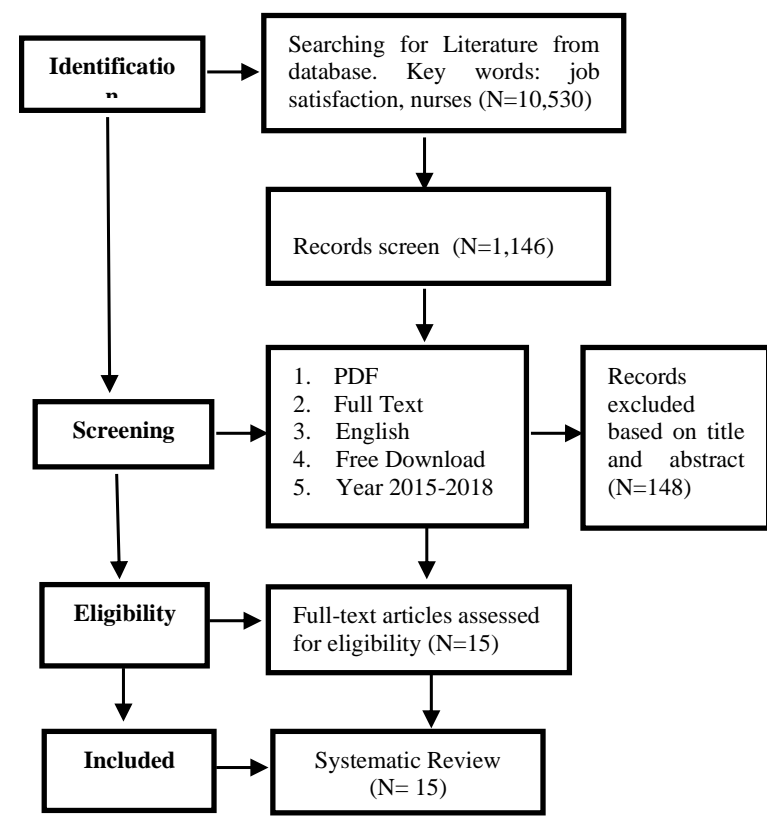

Figure 1. PRISMA flow chart (Moher et al. 2009) this study, the reviews had to be cross-sectional, longitudinal, qualitative or a literature review in terms of their research design and they had to answer the research questions. There were inclusion criteria related to the factors affecting job satisfaction and nurses. There was no limitation on the type of work and regarding the location of the participant's data collection because the focus of the search was to define the factors affecting job satisfaction among the nurses in the hospital. The articles were excluded if the results of the study did not define the factors affecting the job satisfaction of the nurses and if the study was not conducted in a hospital setting. In terms of reducing bias, all of the selected article results were based on a statistic test, the inclusion and exclusion criteria, and the reliability and validity of the instruments used.

\section{RESULTS}

The total literature in this review consisted of 15 published articles with a total of 16,657 respondents and 1 literature review related to the factors affecting job satisfaction among the nurses in the hospital. Several studies have been conducted to define factors affecting job satisfaction among nurses in hospital.

\section{Job Satisfaction}

Job satisfaction is defined as the feelings that an individual has about his/her job is an important nursing outcome that is affected by the quality of the work environment (Boamah et al., 2018). There were 7 questionnaires identified in this systematic review, 5 open question journals, 1 Minnesota job satisfaction scale journal, 1 JSS journal, 2 journals using the General Satisfaction sub scale of the job diagnostic survey, 1 index of work satisfaction journal, 2 MMSS journals and 1Brayfiel and Rothe's index of job satisfaction nursing job satisfaction scale journal.

\section{Work Environment}

There were three studies that examined work environment but only one study suggested that the work environment has an effect on job satisfaction. The work environment factors include teamwork, benefits and rewards, working condition, lack of medical resources, unclear nursing responsibilities at different levels, patient and doctor perceptions, poor leadership skills and discrimination at work (Atefi et al., 2014). The studies showed that the nurses were satisfied with their teamwork and their relationships with other staff nurses. These are important factors related to the nurses' job satisfaction. The Brisbane Practice Environment Scale was used to measure the work environment. Transformational Leadership was measured using the Multifactor Leadership Questionnaire. Resonant leadership was measured using the resonant leadership scale. The CWEQ-II questionnaire was developed by Laschinger et al. (2001) and it was used to measure structural empowerment.

\section{Years of Experience and Level of Qualification}


It was found that years of experience and level of qualification were not influencing factors in relation to the level of job satisfaction.

\section{Nurse to Patient ratio}

The relation between the nurse-to-patient ratio and job satisfaction was significant.

\section{Burnout}

There were two articles that examined burnout. All of them used the Maslach Burnout Inventory (MBI). The results showed there to be a significant relationship between burnout and job satisfaction.

\section{Future career intentions}

Only one study assessed future career intention and job satisfaction. The results showed that most of the respondents agreed that they intended to continue with their nursing career.

\section{Spiritual Feeling}

This theme emerged from the eight FGs during which nurses described factors affecting their job satisfaction. Nurses highlighted a spiritual feeling when taking care of patients. This includes helping sick people and being involved in patient care.

\section{Motivation Factors}

The motivation factors included the task requirements, professional development and a lack of clinical autonomy.

\section{Job Stress}

There were two studies that assessed job stress as a factor affecting job satisfaction. The studies used the Nursing Stress Scale and the Nurse Job Stressor questionnaire was developed in Chinese by Li and Liu to measure job stress. Both of the studies showed there to be no significant relation between job stress and job satisfaction.

\section{Horizontal violence}

Only one study assessed to see if horizontal violence affected job satisfaction. The results showed no significant relation between them. The Negative Acts Questionnaire-Revised (NAQ-R) was used to measure horizontal violence.

\section{DISCUSSION}

The findings of this systematic review suggest that nurse job satisfaction is influenced by many factors. They are including the work environment, the nurse to patient ratio, future career intentions, spiritual feelings and motivation factors. The work environment factors included teamwork, benefits and rewards, the working conditions, a lack of medical resources, unclear nurse responsibilities at different levels, patient and doctor perceptions, poor leadership skills and discrimination at work. Spiritual feelings include helping sick people and their involvement in patient care. Motivation factors include task requirements, professional development and a lack of clinical autonomy (Atefi et al., 2014). There was no significant relation between job stress, years of experience, level of qualification and horizontal violence on job satisfaction.

The present study shows that the environmental factors affect the nurses' satisfaction. The environmental factors show that the nurses who were satisfied with the level of teamwork, who had a relationship with their co-workers in good working conditions, with benefits and rewards, good medical resources, clear nursing responsibilities, good leadership skills and who faced no discrimination at work will increase the nurses' job satisfaction. However, several studies reported that nurses are still dissatisfied about the medical resources and benefit and reward system factors in the hospitals. For the spiritual factors, they show that the nurse were satisfied when helping the patient and being involved in patient care. Last, for motivational factors, they show that opportunities for promotion and development will contribute to the nurses to have higher job satisfaction.

The limitation of the study was the variation in measurement instruments and the number of samples that made the comparison difficult.

Nurse managers and policy makers should improve the nurse's job satisfaction and provide a deeper understanding of the factors that can influence job satisfaction. This is so then strategies can be developed to provide the best way to manage the nursing workforce in the face of increasing pressures.

\section{CONCLUSION}

The results of this review have identified some of the key factors that affect job satisfaction. The result also indicated that high job satisfaction leads to lowering nurse retention and burnout, and it also improves the quality of patient care. However, there were several studies that reported that not all hospitals pay attention to the factors affecting the nurses' job satisfaction. Nurse managers and policy makers play an important role in providing nursing job satisfaction in hospitals.

\section{REFERENCES}

Abduelaal Abduelazeez, A. E., \& Mohammed Nouri, M. (2016). Job Satisfaction and Related Factors among Intensive Care Nurses in Governmental Hospitals at Khartoum State - Sudan. Journal of Community \& Public Health Nursing. https://doi.org/10.4172/2471-9846.1000114

Akman, O., Ozturk, C., Bektas, M., Ayar, D., \& Armstrong, M. A. (2016). Job satisfaction and burnout among paediatric nurses. Journal of Nursing https://doi.org/10.1111/jonm.12399

Alghamdi, M. G., Topp, R., \& AlYami, M. S. (2018). The effect of gender on transformational leadership and job satisfaction among Saudi nurses. Journal of Advanced Nursing. https://doi.org/10.1111/jan.13385

Alostaz, Z. (2016). Job Satisfaction Among Critical 
Care Nurses In Al Baha, Saudi Arabia: A CrossSectional Study. Gulf Medical Journal.

Ashley, C., Peters, K., Brown, A., \& Halcomb, E. (2018). Work satisfaction and future career intentions of experienced nurses transitioning to primary health care employment. Journal of Nursing Management. https://doi.org/10.1111/jonm.12597

Atefi, N., Abdullah, K. L., Wong, L. P., \& Mazlom, R. (2014). Factors influencing registered nurses perception of their overall job satisfaction: A qualitative study. International Nursing Review. https://doi.org/10.1111/inr.12112

Bawafaa, E., Wong, C. A., \& Laschinger, H. (2015). The influence of resonant leadership on the structural empowerment and job satisfaction of registered nurses. Journal of Research in Nursing. https://doi.org/10.1177/1744987115603441

Biegger, A., De Geest, S., Schubert, M., \& Ausserhofer, D. (2016). The "magnetic forces" of Swiss acute care hospitals: A secondary data analysis on nurses' job satisfaction and their intention to leave their current job. NursingPlus Open. https://doi.org/10.1016/j.npls.2016.01.002

Boamah, S. A., Spence Laschinger, H. K., Wong, C., \& Clarke, S. (2018). Effect of transformational leadership on job satisfaction and patient safety outcomes. Nursing Outlook. https://doi.org/10.1016/j.outlook.2017.10.004

Déry, J., Clarke, S. P., D'Amour, D., \& Blais, R. (2018). Scope of Nursing Practice in a Tertiary Pediatric Setting: Associations With Nurse and Job Characteristics and Job Satisfaction. Journal of Nursing Scholarship, 50(1), 56-64. https://doi.org/10.1111/jnu.12352

Douglas, C., \& Bonner, A. (2015). Haemodialysis Nurse
Satisfaction , Stress and Burnout Work Environment, Job Satisfaction, Stress and Burnout Among Haemodialysis Nurses Bronwyn Hayes RN, MHlthSci, Clint Douglas RN , PhD and Ann Bonner $R N$, PhD School of Nursing, Queensland Universit. https://doi.org/10.1111/jonm.12184/abstract.

Fallatah, O. K., \& Mahran, S. (2017). Nursing Practice Environment And Job Satisfaction From The Perspective of Staff Nurses. 6(6), 82-86. https://doi.org/10.9790/1959-0606078286

Halcomb, E., Smyth, E., \& McInnes, S. (2018). Job satisfaction and career intentions of registered nurses in primary health care: an integrative review. BMC Family Practice, 19(1). https://doi.org/10.1186/s12875-018-0819-1

Moher, D., Liberati, A., Tetzlaff, J., Altman, D. G., Altman, D., Antes, G., ... Tugwell, P. (2009). Preferred reporting items for systematic reviews and meta-analyses: The PRISMA statement. Annals of Internal Medicine, Vol. 151, pp. 264-269. https://doi.org/10.7326/0003-4819-151-4200908180-00135

Purpora, C., \& Blegen, M. A. (2015). Job satisfaction and horizontal violence in hospital staff registered nurses: The mediating role of peer relationships. Journal of Clinical Nursing. https://doi.org/10.1111/jocn.12818

Wu, X., Li, J., Liu, G., Liu, Y., Cao, J., \& Jia, Z. (2018). The effects of emotional labor and competency on job satisfaction in nurses of China: A nationwide cross-sectional survey. International Journal of Nursing https://doi.org/10.1016/j.ijnss.2018.08.001 